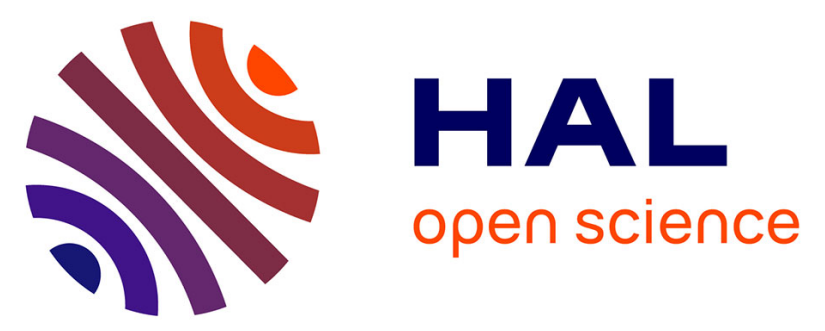

\title{
ITO-Free Organic Photovoltaic Modules Based on Fluorinated Polymers Deposited from Non-Halogenated Solution: A Major Step Toward Large-Scale Module Production
}

Olzhas. Ibraikulov, Jing Wang, Narayanaswamy Kamatham, Benoît Heinrich, Stéphane Méry, Markus Kohlstädt, Uli Würfel, Stéphanie Ferry, Nicolas Leclerc, Thomas Heiser, et al.

\section{- To cite this version:}

Olzhas. Ibraikulov, Jing Wang, Narayanaswamy Kamatham, Benoît Heinrich, Stéphane Méry, et al.. ITO-Free Organic Photovoltaic Modules Based on Fluorinated Polymers Deposited from NonHalogenated Solution: A Major Step Toward Large-Scale Module Production. Solar RRL, 2019, pp.1900273. 10.1002/solr.201900273 . hal-02370300

\section{HAL Id: hal-02370300 https://hal.science/hal-02370300}

Submitted on 19 Nov 2021

HAL is a multi-disciplinary open access archive for the deposit and dissemination of scientific research documents, whether they are published or not. The documents may come from teaching and research institutions in France or abroad, or from public or private research centers.
L'archive ouverte pluridisciplinaire HAL, est destinée au dépôt et à la diffusion de documents scientifiques de niveau recherche, publiés ou non, émanant des établissements d'enseignement et de recherche français ou étrangers, des laboratoires publics ou privés. 


\title{
ITO-Free Organic Photovoltaic Modules Based on Fluorinated Polymers Deposited from Non-Halogenated Solution: A Major Step Toward Large-Scale Module Production
}

\author{
Olzhas. A. Ibraikulov, Jing Wang, Narayanaswamy Kamatham, Benoît Heinrich, \\ Stéphane Méry, Markus Kohlstädt, - Uli Würfel, Stéphanie Ferry, Nicolas Leder, \\ Thomas Heiser, and Patrick Lévêque
}

Several bottlenecks need to be passed to reach market readiness for organic photovoltaic modules. To avoid scarce and costly materials such as indium is an important technological issue. To be able to process the active layerfrom solutions prepared from non-halogenated solvents and harmless additives is also a crucial step. Herein, a fluorinated polymer is used as an electron-donor material and $\mathrm{PC}_{71} \mathrm{BM}$ as an electron-accepting material in a bulk-heterojunction configuration, to demonstrate that indium-tin-oxide (ITO)-free modules with an active area greater than $60 \mathrm{~cm}^{2}$ and processed from non-halogenated solvents and harmless additives can reach a high power conversion efficiency of above $6 \%$.
(BHJ) solution-processed active layers have experienced a rapid growth in their performances. With power conversion efficiency (PCE) values of more than $15 \%$ recently reported for single junctions, ${ }^{[1,2]} \mathrm{OPV}$ devices exhibit, nowadays, higher performances than amorphous silicon solar cells. Moreover, the operational lifetime has been considerably extended to approach 10 years, $^{[3]}$ and extrapolated lifetimes greater than 20 years have even been reported recently. ${ }^{[4]}$

These very high efficiencies have essentially been obtained from fluorine-

\section{Introduction}

The versatile and finely tunable optoelectronic properties of organic semiconductors make them appealing candidates for photovoltaic applications. Organic photovoltaic (OPV) devices can show valuable features, such as flexibility, semi-transparency, color tuning, in addition to a low-cost processing. Over the past 20 years, because of the combined efforts in chemical design and device engineering, OPV devices based on bulk-heterojunction

Dr. O. A. Ibraikulov, J. Wang, Prof. T. Heiser, Dr. P. Lévêque

Laboratoire ICube

Université de Strasbourg

CNRS, UMR 7357

23 rue du Loess, Strasbourg 67037, France

E-mail: patrick.leveque@unistra.fr

Dr. N. Kamatham, Dr. B. Heinrich, Dr. S. Méry

Institut de Physique et Chimie des Matériaux de Strasbourg (IPCMS)

Université de Strasbourg

CNRS

23 rue du Loess, Strasbourg 67034, France

Dr. M. Kohlstädt

Freiburg Materials Research Center FMF

University of Freiburg

Stefan-Meier-Str. 21, Freiburg 79104, Germany

E-mail: markus.kohlstaedt@fmf.uni-freiburg.de containing polymers ${ }^{[5]}$ as electron-donor materials and nonfullerene acceptors (NFAs) ${ }^{[6]}$ as electron-acceptor materials, and they represent a significant step toward elaboration of OPV modules. For market readiness, however, it remains crucial that highly efficient OPV lab-scale devices usually produced from scarce and costly materials (e.g., indium) and processed under harmful conditions (e.g., hot dichlorobenzene solvent) be upscaled to large-surface ITO-free modules, and elaborated using non-halogenated solvents and harmless

\author{
Dr. U. Würfel \\ Emerging Photovoltaic Technologies \\ Fraunhofer Institute for Solar Energy Systems ISE \\ Heidenhofstr. 2, Freiburg 79110, Germany \\ S. Ferry, Dr. N. Leclerc \\ Institut de Chimie et Procédés pour l'Energie, l'Environnement et la Santé \\ (ICPEES) \\ Université de Strasbourg \\ CNRS, UMR 7515 \\ 25 rue Becquerel, Strasbourg 67087, Cedex 02, France \\ E-mail: leclercn@unistra.fr
}


additives. To date, the number of reports of large OPV modules $\left(>10 \mathrm{~cm}^{2}\right)$ is rather low ${ }^{[7-10]}$ and becomes scarce if one excludes the presence of ITO and considers a process using ecofriendly conditions. ${ }^{[11-13]}$

We recently published high photovoltaic performances obtained with an electron-donor fluorinated copolymer, ${ }^{[14]}$ named PF2, and a fullerene derivative, showing efficiencies greater than $10 \%$ on $12 \mathrm{~mm}^{2}$-sized devices elaborated from hot ortho-dichlorobenzene (o-DCB) solution and using an indium-containing electrode. The structure of PF2 is shown in Figure 1, and its synthesis has been previously described. ${ }^{[14]}$ PF2 exhibits outstanding characteristics, such as well-adjusted frontier orbital energy levels as compared with [6,6]-phenyl-C71butyric acid methyl ester $\left(\mathrm{PC}_{71} \mathrm{BM}\right)$, excellent light-harvesting capabilities, and high out-of-plane charge transport properties together with a high morphology robustness upon blending, which translate into high photoconversion efficiency in lab-scale devices.

In a very recent paper, Chochos et al. reported a comprehensive analysis, based on data from the literature, of the synthesis upscalability of efficient low bandgap copolymers. ${ }^{[15]}$ To this end, they introduced the synthetic complexity (SC) and the figure of merit (FOM), as valuable indices regarding electron-donor polymers. ${ }^{[16]} \mathrm{SC}$ is defined by Equation (1), where NSS is the number of synthetic steps required for the synthesis of the monomers, RY is the yield of the monomers synthesis, NUO is the number of unit operations for the purification of the comonomers, NCC is the number of the column chromatographic steps for the purification of the comonomers, and $\mathrm{NHC}$ is the safety characteristics of the chemicals used for their preparation.

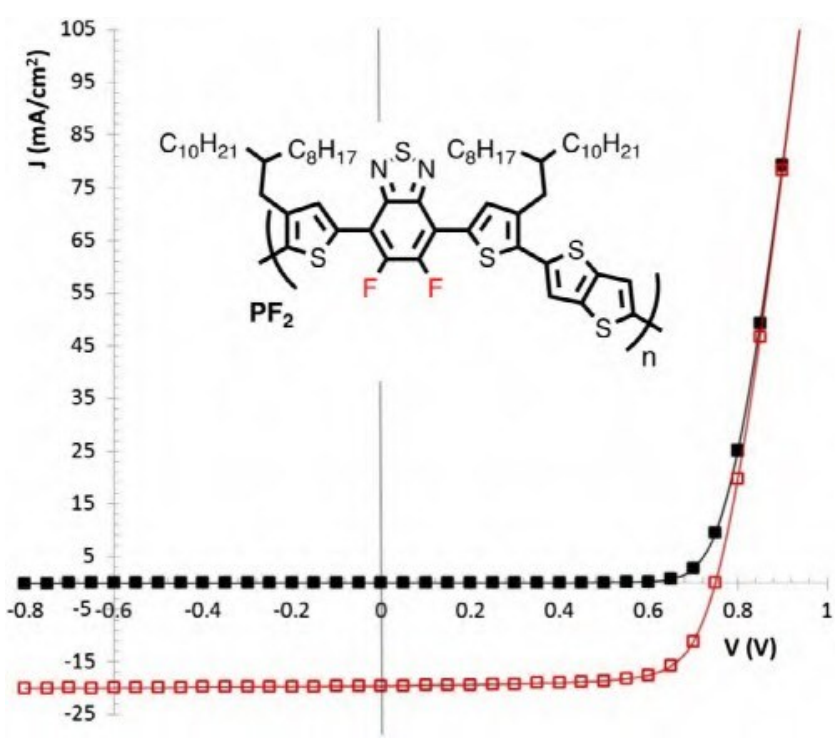

Figure 1. Fluorinated polymer (PF2) structure and $J-V$ curves measured on our hero lab-scale $12 \mathrm{~mm}^{2}$ diode in the dark (full squares) and under standard AM1.5Gillumination (open squares). Thestructure of thediode was (ITO/PEIE/active layer/ $/ \mathrm{MOO}_{3} / \mathrm{Ag}$ ) with an active layer processed from hot o-DCB with a PF2 concentration of $3.5 \mathrm{mg} \mathrm{mL}^{-1}$ and a (1:1.5) PF2: $\mathrm{PC}_{71} \mathrm{BM}$ weightratio.
$\frac{\mathrm{SC} 1 / 435 \frac{\mathrm{NSS}}{\mathrm{NSS}_{\max }} \mathrm{p} 25 \frac{\log \mathrm{NY} p}{\log \mathrm{RY}_{\max } \mathrm{p}} \mathrm{NUO}_{\max }}{\mathrm{NCC}}$ parameter from the list of efficient low bandgap electron-donor copolymers from the literature, and the relative importance of each term was empirically determined to calculate an SC parameter ranging from 0 to 100 . The FOM is calculated by dividing the SC parameter by the measured PCE. As SC can be considered as a rough estimate of the polymer cost, FOM represents the cost-efficiency balance of a given donor material.

Among polymer models used in Chochos's review, $\mathrm{PF} 2$ polymer can be found under the name PDTBT-TT. An SC of $60.66 \%$ was reported for PF2, which led to a calculated FOM value of 5.78 using the $10.5 \%$ PCE value we recently measured (Figure 1). This FOM of about 5.8 is one of the lowest values reached by a high-efficiency electron-donor polymer with a PCE higher than 9\% (Supporting Information). Such a low FOM value makes this

PF2 polymer as a promising candidate for upscaling toward

module fabrication. To this aim, we further investigated the performance of this polymer in OPV devices using greener processing conditions and larger active area modules. In this study, non-halogenated solvents have been tested together with harm-

less additives to reach similar efficiencies on lab-scale and ITO-containing devices. Then, larger area OPV modules have been elaborated, with a special focus on ITO-free devices. We demonstrate that ITO-free modules with an active area greater than $60 \mathrm{~cm}^{2}$ and processed from non-halogenated solvents and harmless additives could reach a high PCE of above $6 \%$.

\section{Results and Discussion}

Using the inverted structure (ITO/polyethylenimine ethoxylated (PEIE)/active layer/ $\mathrm{MoO}_{3} / \mathrm{Ag}$ ), hot $o$-DCB as a processing solvent, and PF2:PC ${ }_{71} \mathrm{BM}$ as an active layer, we obtained a maximum PCE of $10.5 \%$ on a $12 \mathrm{~mm}^{2}$ lab-scale diode (Figure 1 and Supporting Information for elaboration details), which is a slight improvement over our previously published results. On the road toward modules processed from more ecofriendly solvents, the first step consists in the selection and testing of suitable non-halogenated solvents. Following previous studies reported in the literature, two solvents have been chosen as they have shown to be efficient solvents (with additives) for fluorinated polymers having a conjugated backbone more or less close to PF2. ${ }^{[17,18]}$ The first solvent is $o$-xylene $(o-X Y)$ and the second one 1,2,4-trimethylbenzene (TMB) referred to as "green" solvents, ${ }^{[19]}$ as compared with standard halogenated solvents commonly used in OPV fabrication. The Hansen solubility parameters of PF2 have been experimentally determined (see Supporting Information), and the relative energy difference (RED) between PF2, $o-\mathrm{XY}$, and TMB have been calculated. For both solvents, RED is close to 1 (1.03 and 0.99 for TMB and $o-\mathrm{XY}$, respectively), meaning that PF2 is right at the border between solubility and non-solubility for both solvents. The UV-visible spectra as a function of the solution temperature for diluted PF2 solutions (see Supporting Information for details) can be found in Figure 2. For comparison purpose, the UV spectrum 
(a)

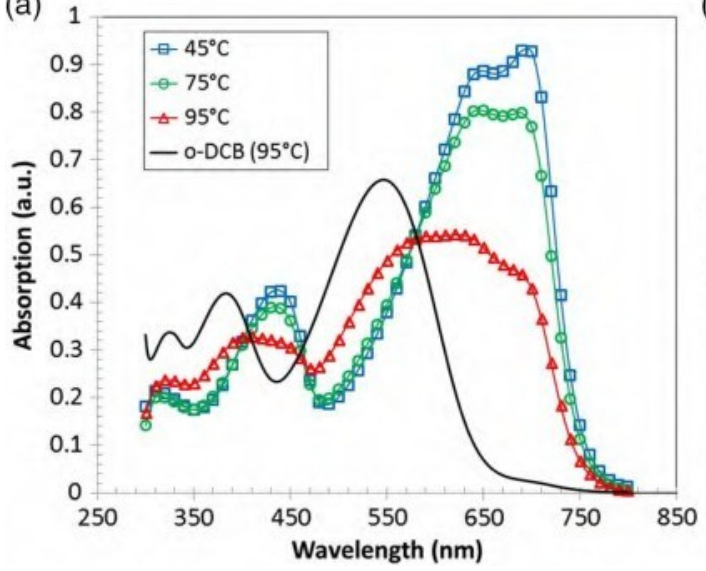

(b)

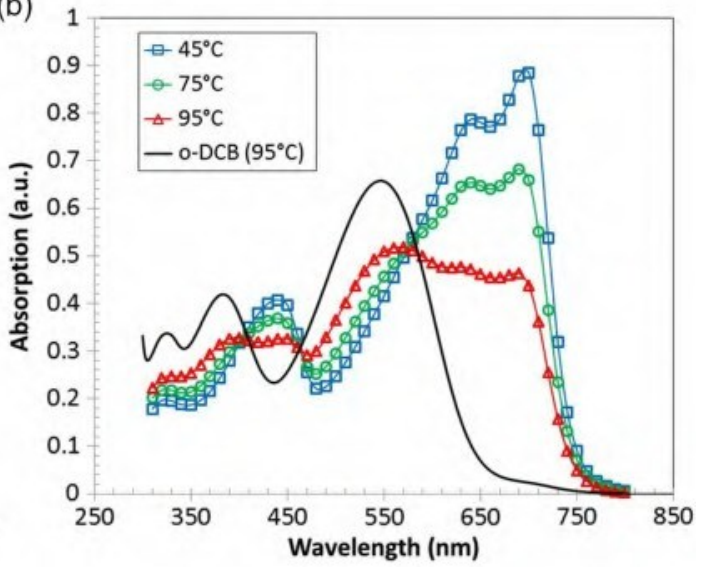

Figure 2. PF2 polymer absorption spectra in dilute solution as a function of the temperature in a) $o_{-} \mathrm{XY}\left(0.05 \mathrm{mg} \mathrm{mL}^{-1}\right)$ and b) TMB $\left(0.1 \mathrm{mg} \mathrm{mL}^{-1}\right)$. For sake of comparison, the absorption spectrum of PF2 in $0-\mathrm{DCB}\left(0.01 \mathrm{mg} \mathrm{mL}^{-1}\right)$ at $95^{\circ} \mathrm{C}$ is also plotted, as a continuous line. All spectra were recorded at heating.

of PF2 in dilute $o$-DCB solutions at high temperature has been reported in each figure (black curves). Note that different PF2 batches were used for different solvents. For $o-\mathrm{XY}$ and TMB, the $M_{n}$ values were measured as equal to 45 and $53 \mathrm{kDa}$, respectively. For $o$-DCB solutions, an $M_{n}$ value of $35 \mathrm{kDa}$ was measured.

At $95^{\circ} \mathrm{C}$ in $o$-DCB (continuous line in Figure 2 and corresponding to the processing temperature for the solar-cell elaboration), two broad absorption peaks are measured at around 390 and $553 \mathrm{~nm}$, which are most likely due to $\pi-\boldsymbol{T}$ and intramolecular charge transfer transitions, respectively, as often observed in the literature for donor-acceptor alternating copolymers. ${ }^{[20]}$ At lower temperatures, $o$-DCB PF2 solution spectra exhibit three new peaks (around 440, 636, and $695 \mathrm{~nm}$ : see Supporting Information) with an amplitude increasing, whereas the peaks observed at $95{ }^{\circ} \mathrm{C}$ decrease in amplitude. ${ }^{[14]}$ Those three new vibronic peaks and their reversible behavior as a function of temperature have been studied in details elsewhere ${ }^{[21]}$ and are the signature of temperature-dependent aggregation in solution. ${ }^{[5]}$ The very same behavior is seen with both non-halogenated solvents investigated here, but occurs at different temperatures. Indeed, the PF2 absorption spectrum at $95{ }^{\circ} \mathrm{C}$ in TMB is very similar to the $o$-DCB one at $75{ }^{\circ} \mathrm{C}$. This strongly suggests that a small part of the polymer chains in the non-halogenated solvents remains in aggregated state even at $95{ }^{\circ} \mathrm{C}$.

Photovoltaic lab-scale devices have been optimized for the two non-halogenated solvents (see Supporting Information), leading systematically to an optimal(PF2:PC ${ }_{71} \mathrm{BM}$ ) weightratio of(1:1.5), similar to what was obtained with $o-\mathrm{DCB} .{ }^{[14]}$ Blends were processed from hot solutions $\left(\# 05{ }^{\circ} \mathrm{C}\right.$, when the vibronic peaks no longer dominate the absorption spectra in solution) and deposited by spin-coating on pre-heated substrates at the same temperature. Two different previously reported hydrocarbon additives were used depending on the solvent ${ }^{[6,22]}$ to obtain optimized photovoltaic devices. For $o$-XY, $p$-anisaldehyde (AA) has been tested as an additive, whereas for TMB, 1-phenylnaphthalene (PN) was used as an additive. In both non-halogenated solvents, the optimum additive concentration was $3 \%$ by volume. No post-deposition treatment, such as thermal or solvent annealing, was applied before the thermal evaporation of the hole-collecting electrode. All the details on the processing conditions and device configuration are given in the Supporting Information. The current density-voltage characteristics and external quantum efficiency (EQE) are given in Figure 3. Corresponding photovoltaic parameters are listed in Table 1 together with photovoltaic parameters of previously optimized devices with a similar structure and fabricated using $o$-DCB solutions. ${ }^{[14]}$

The open-circuit voltage $\left(V_{\mathrm{oc}}\right)$ is weakly depending on the solvent used to elaborate the photovoltaic devices. By cyclic voltammetry, an highest occupied molecular orbital (HOMO) energy of $5.4 \mathrm{eV}$ has been measured for PF2. As the expected open-circuit voltage $\left(V_{\mathrm{oc}}\right)$ in $\mathrm{BHJ}$ solar cells is proportional to the difference between the HOMO of the electron donor and the lowest unoccupied molecular orbital (LUMO) energy of the electron acceptor minus an empirically determined $0.3 \mathrm{~V}^{[23]} \mathrm{a}$ $V_{\mathrm{oc}}$ in the $800 \mathrm{mV}$ range is expected from $\mathrm{PF} 2 \mathrm{PC}_{71} \mathrm{BM}$-based blends in optimized devices, taking $-4.3 \mathrm{eV}$ as the LUMO level for $\mathrm{PC}_{71} \mathrm{BM}^{\left[{ }^{[24]}\right.}$ The results obtained for the different solvents are consistent with the estimated $V_{\text {oc }}$. Despite a high fill factor (FF), both non-halogenated solvent devices present a significantly lower $J_{\mathrm{sc}}$ value than the $o$-DCB ones, resulting in a comparably lower efficiency. Nevertheless, the PCE of $9 \%$ measured on devices processed from TMB solutions stays among the highest reported values for devices processed from hydrocarbon solvents without any post-thermal treatments and using $\mathrm{PC}_{71} \mathrm{BM}$ as an electron acceptor.

To understand the high PCEs obtained for all solvents, hole outof-plane mobility has been estimated using space-charge limited current (SCLC) devices. Hole-only diode elaboration procedure as well as $(I-V)$ characteristics can be found in the Supporting Information. The hole mobility for pure PF2 as well as for $\mathrm{PF} 2: \mathrm{PC}_{71} \mathrm{BM}$ blends (1:1.5 weight ratio) is reported in Table 2 .

Whatever the solvent used, there is no significant variation of the out-of-plane hole mobility for the pure PF2 (from 7 to $10 \times 10^{-3} \mathrm{~cm}^{2} \mathrm{~V}^{-1} \mathrm{~s}^{-1}$ ) or for the PF2:PC ${ }_{71} \mathrm{BM}$ blend (from 3 to $8 \times 0^{-3} \mathrm{~cm}^{2} \mathrm{~V}^{-1} \mathrm{~s}^{-1}$ ) as a function of the solvent used. After blending, the out-of-plane hole-mobility is only divided by a factor of 2 when $o-\mathrm{XY}$ or TMB is used as solvents and almost unchanged in the case of $o$-DCB solutions. The out-of-plane electron mobility 

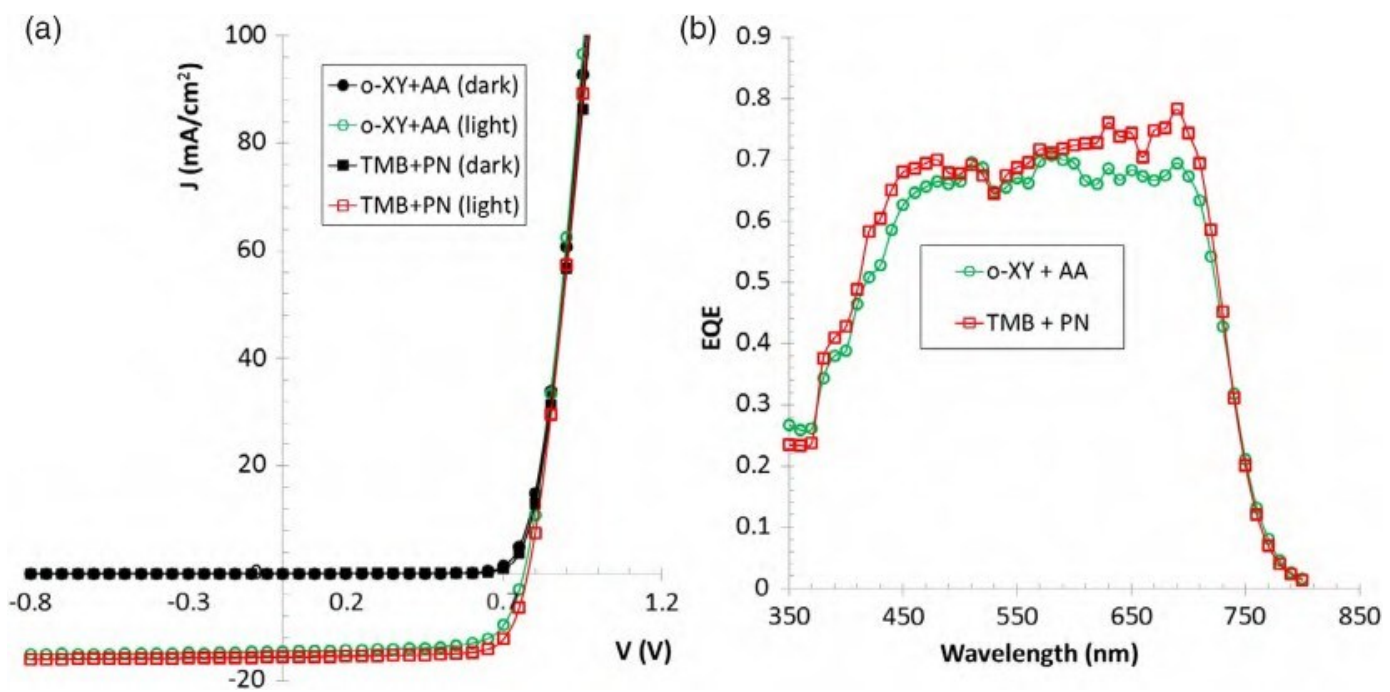

Figure 3. a) $J-V$ measurements for ( $P F 2: P C_{71} B M$ ) photovoltaic devices (active area: $12 \mathrm{~mm}^{2}$ ) processed from o- $X Y$ solution with $A A$ as an additive (circles) and from TMB solution with PN as an additive (squares). $J-V$ curves in the dark are represented by closed symbols, and $J-V$ curves under standard AM1.5G illumination are represented by open symbols. b) Corresponding EQE measurements.

Table 1. Photovoltaic parameters measured on (PF2: $\left.\mathrm{PC}_{71} \mathrm{BM}\right)$ photovoltaic devices (active area: $12 \mathrm{~mm}^{2}$ ) processed from different solutions. The $o$-DCB parameters are higher than the one previously published $^{[14]}$ due to a continuous elaboration process improvement.

\begin{tabular}{lccccc}
\hline Solvent & Additive & $V_{o c}[\mathrm{~V}]$ & $J_{\mathrm{sc}}\left[\mathrm{mA} \mathrm{cm}^{-2}\right]$ & $\mathrm{FF}[\%]$ & $\mathrm{PCE}[\%]^{\mathrm{a})}$ \\
\hline o-XY & $\mathrm{AA}$ & 0.77 & 14.7 & 70 & $8.0(7.9)$ \\
TMB & $\mathrm{PN}$ & 0.78 & 15.3 & 76 & $9.1(9.0)$ \\
o-DCB & - & 0.75 & 19.5 & 72 & $10.5(9.9)$ \\
\hline
\end{tabular}

a)The average PCE measured on at least ten different diodes is indicated within parentheses.

Table 2. Hole mobility extracted from SCLC measurements.

\begin{tabular}{lcc}
\hline Material & Solvent mixture & $\mu_{\mathrm{h}}\left[\mathrm{cm}^{2} \mathrm{~V}^{-1} \mathrm{~s}^{-1}\right]$ \\
\hline $\mathrm{PF} 2$ & $o-\mathrm{XY}$ & $(7 \mathrm{~T} 2) \times 10^{-3}$ \\
$\mathrm{PF} 2: \mathrm{PC}_{71} \mathrm{BM}$ & ${ }^{-} \mathrm{XY}+\mathrm{AA}$ & $(3 \mathrm{~T} 1) \times 10^{-3}$ \\
$\mathrm{PF} 2$ & $\mathrm{TMB}$ & $(10 \mathrm{~T} 1) \times 10^{-3}$ \\
$\mathrm{PF} 2: \mathrm{PC}_{71} \mathrm{BM}$ & $\mathrm{TMB}+\mathrm{PN}$ & $(5 \mathrm{~T} 1) \times 10^{-3}$ \\
$\mathrm{PF} 2$ & $o-\mathrm{DCB}$ & $(9 \mathrm{~T} 1) \times 10^{-3}$ \\
$\mathrm{PF} 2: \mathrm{PC}_{71} \mathrm{BM}$ & $o-\mathrm{DCB}$ & $(8 \mathrm{~T} 1) \times 10^{-3}$ \\
\hline
\end{tabular}

has been measured on electron-only devices elaborated from an $o$ DCB PF2:PC ${ }_{71} \mathrm{BM}$ solution. It was in the same range as the outof-plane hole mobility ( $\left.610 \mathbf{X}^{3} \mathrm{~cm}^{2} \mathrm{~V}^{-1} \mathrm{~s}^{-1}\right)$.

Furthermore, structural experiments for the pure polymer and for blends have been performed using grazing incidence wideangle X-ray scattering (GIWAXS) experiments. The sample preparation is described in the Supporting Information, and the blend weight ratios are the same as the one used in OPV devices. For pure PF2 (Figure 4a,c), standing and in-plane lamellar orientations can be clearly distinguished, i.e., the polymers adopt mixed face-on/edge-on orientations independently of the solvent. The PF2:PC ${ }_{71} \mathrm{BM}$ blends (1:1.5 weight ratio) deposited on a conducting sublayer (PEIE or $\mathrm{ZnO}$ ) exhibit a face-on proportion of about $55-60 \%$ in all solvent conditions (halogenated and non-halogenated solvents). This is in-line with the high SCLC hole mobility measured in blends.

For scaling up the PF2-based devices to areas more relevant for future applications, the viability of the whole cell stack in terms of cost and stability has to be considered. Nowadays, commonly used ITO electrodes are replaced by transparent electrode stacks consisting of a thin, conductive, and transparent metal (M) layer sandwiched between two dielectric (D) layers, which are usually metal oxides. On flexible substrates, these so-called dielectric-metal-dielectric (DMD) electrodes show less sheet resistance while being mechanically much more robust, which is in part due to the much thinner layers of the brittle dielectric material. $^{[25]}$ Still, some of these DMD electrodes contain ITO, ${ }^{[26,27]}$ which is known to have a high cost and energy share in OPV devices. Besides ITO-free DMD electrodes, a viable alternative is to use substrate-sided opaque metal electrodes and a metal grid electrode on top of the cell stack. ${ }^{[28]}$ Together with the well-established material system poly(3-hexylthiophene): PCBM (P3HT:PCBM), ITO-free organic solar cells with PCEs similar to ITO-based devices and a remarkably high stability under damp heat and continuous illumination conditions have been demonstrated. ${ }^{[29]}$ For this reason, ITO-free OPV devices based on the material system $\mathrm{PF} 2: \mathrm{PC}_{71} \mathrm{BM}$ have been realized using this architecture (Figure $5 \mathrm{a}$ ) and using a modified aluminum electrode as opaque back contact, similar to the one published in the previous study. ${ }^{[2]}$ Devices were fabricated with photoactive layers processed from either $o-\mathrm{XY}$ with AA additive or TMB with PN additive. The current density-voltage characteristics of such devices are given in Figure 5b. Corresponding photovoltaic parameters are listed in Table 3 .

ITO-free devices with photoactive layers processed from $o$-XY $\mathrm{p}$ AA and TMB $\mathrm{p}$ PN had very similar values for both 

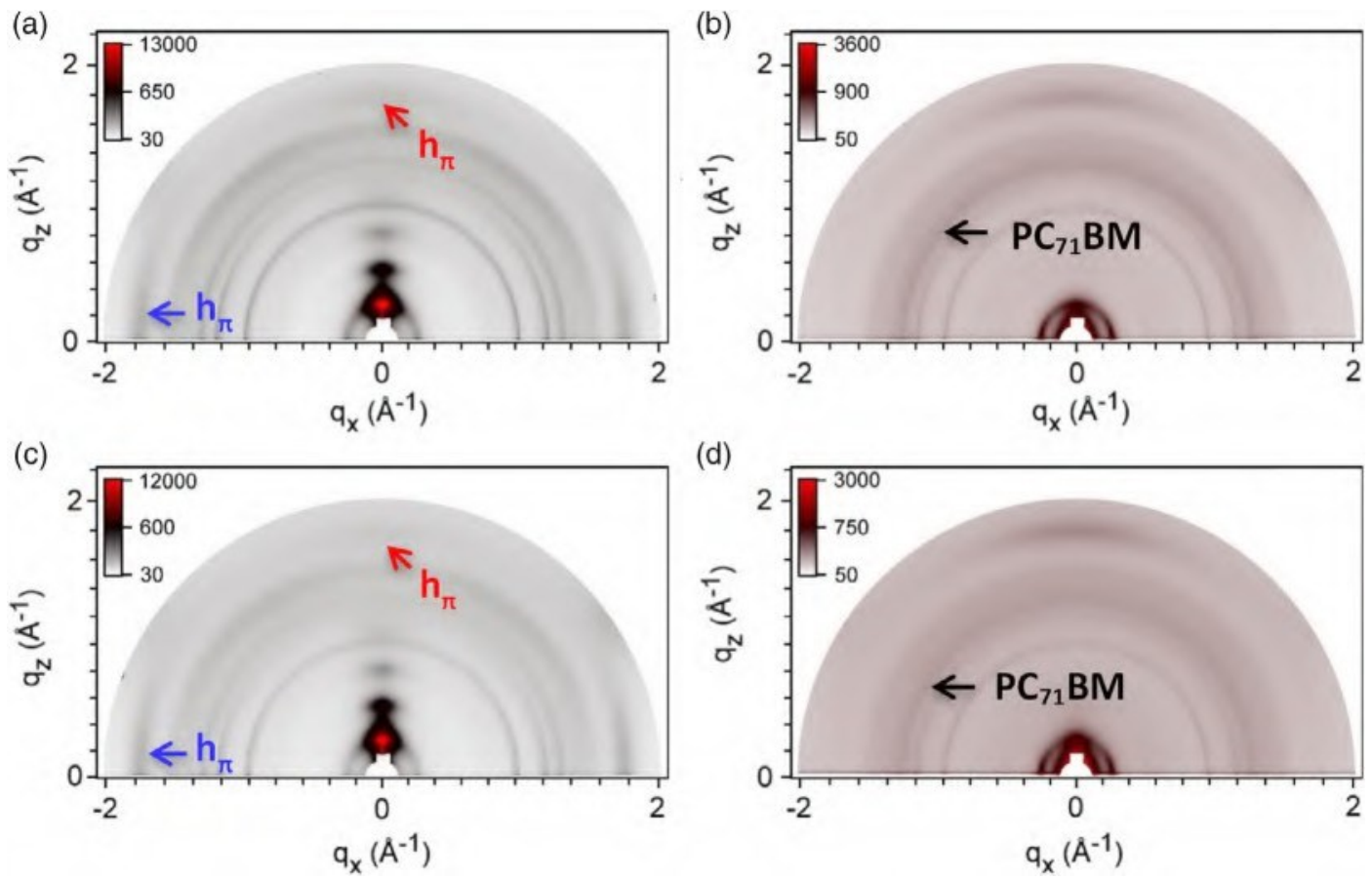

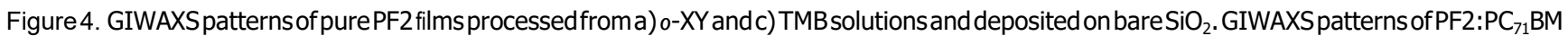
$(1: 1.5)$ blends in films processed from $b)(o-X Y+A A)$ and $d)(T M B+P N)$ and deposited on $Z n O$. Two major populations of domain orientation can be distinguished, namely, red $h_{\pi}$ spots for face-on and blue $h_{\pi}$ spots for edge-on.
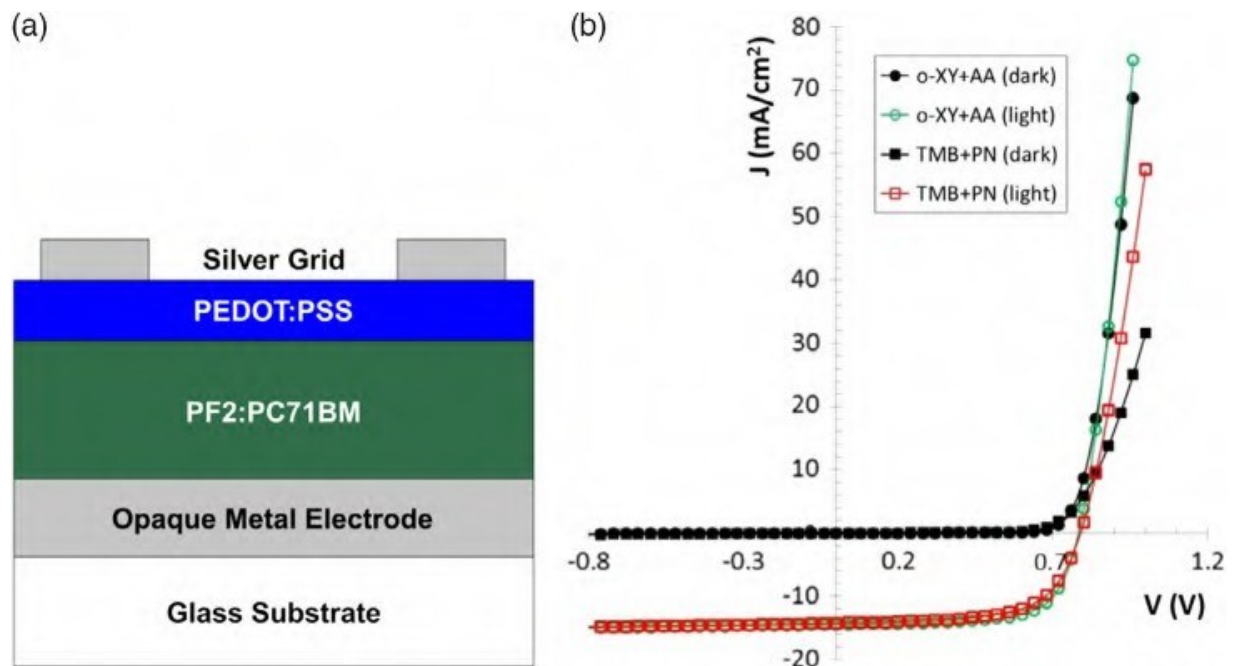

Figure 5. a) Schemeof the cell architecture of ITO-free OPV cellsand modules fabricated in this work. b) J-Vmeasurementsfor (PF2:PC $\left.{ }_{71} B M\right)$ photovoltaic devices (active area: $9.25 \mathrm{~mm}^{2}$ ) processed from o-XY solution with AA as an additive (circles) and from TMB solution with PN as an additive (squares). $J-V$ curves in the dark are represented by closed symbols, and $J-V$ curves under standard AM1.5G illumination are represented by open symbols.

the short-circuit current density $\left(J_{\mathrm{sc}}\right)$ and the open-circuit voltage $\left(V_{\mathrm{oc}}\right)$, indicating that the charge carrier generation is not affected by the choice of solvent and that there are no additional recombination losses for one of the two systems. Nevertheless, a lower FF was observed when TM\$PN was used, originating from a higher series resistance of the devices, as judged by interpretation of the corresponding $J-V$ curves.
It might have been induced by the different evaporation rates for solvents and additives of the photoactive layers, which have been processed in parallel. Optimized processing of the TMBPPN based devices could lead to enhanced efficiency but was not investigated further. For scaling up to OPV modules, the ITO-free cell architecture with $\mathrm{PF} 2: \mathrm{PC}_{71} \mathrm{BM}$ processed from $o$-XY p AA was used. 
Table 3. Photovoltaic parameters measured on (PF2:PC $\left.{ }_{71} \mathrm{BM}\right)$ photovoltaic devices (active area: $9.25 \mathrm{~mm}^{2}$ ) processed from different solutions.

\begin{tabular}{lccccc}
\hline Solvent $^{\text {a) }}$ & Additive & $V_{\mathrm{oc}}[\mathrm{V}]$ & $\mathrm{Jsc}_{\mathrm{sc}}\left[\mathrm{mA} \mathrm{cm}^{-2}\right]$ & FF [\%] & PCE [\%] \\
\hline o-XY & AA & $0.78(0.78)$ & $14.5(13.9)$ & $69(66)$ & $7.8(7.1)$ \\
TMB & PN & $0.79(0.78)$ & $14.2(13.8)$ & $64(60)$ & $7.2(6.4)$ \\
\hline
\end{tabular}

a)The average values from four individual devices are indicated within parentheses.

To realize the module structure, 15 cells were monolithically connected in series and the organic layers deposited by bladecoating. After optimization of the coating parameters, especially with regard to solution and substrate temperature as well as processing of the photoactive layer, OPV modules with an active area of $66 \mathrm{~cm}^{2}$ (geometrical fill factor [GFF]: 69\%) and a PCE of $6.1 \%$ could be realized (Figure 6 and Table 4 ).

A high $V_{\mathrm{OC}}$ of $11.7 \mathrm{~V}$ was observed for the OPV modules, corresponding to a $V_{\mathrm{OC}}$ of $0.78 \mathrm{~V}$ for one of the 15 serially connected cells. This exactly matches the value for small-scale devices (see Table 3), indicating that through the serial connection and upscaling, no voltage losses caused by, e.g., reduced parallel resistance due to local-coating defects have arisen. Furthermore, a reduced $\mathrm{FF}$ and $J_{\mathrm{SC}}$ were found, the later one being $13.3 \mathrm{~mA} \mathrm{~cm}^{-2}$ per cell, which we attribute to increased serial resistance of the larger area solar cells.

\section{Conclusion}

We show in this study that a fluorinated polymer (PF2) used as an electron-donor material blended with $\mathrm{PC}_{71} \mathrm{BM}$ as an electronacceptor material could lead to a PCE of $10.5 \%$ using ITOcontaining lab-scale $\left(12 \mathrm{~mm}^{2}\right)$ solar cells processed from a halogenated solvent $(O-\mathrm{DCB})$. The very same active layer was then processed using non-halogenated solvents (o-XY and TMB) with harmless additives (AA with $o-\mathrm{XY}$ and $\mathrm{PN}$ for TMB) using the same device architecture. The efficiency dropped relatively by
Table 4. Photovoltaic parameters measured on (PF2:PC ${ }_{71} \mathrm{BM}$ ) ITO-free photovoltaic modules (active area: $66 \mathrm{~cm}^{2}$, GFF: 69\%) with 15 serially connected cells. For comparison with small-scale solar cells, the "per cell" values were calculated dividing and multiplying the module values for $v_{\mathrm{OC}}$ and $J_{S C}$ by the number of cells.

\begin{tabular}{|c|c|c|c|c|}
\hline Area & $V_{o c}[\mathrm{~V}]$ & $J_{\mathrm{sc}}\left[\mathrm{mA} \mathrm{cm}^{-2}\right]$ & $\mathrm{FF}[\%]$ & PCE [\%] \\
\hline Module $\left(66 \mathrm{~cm}^{2}\right)$ & 11.7 & 0.89 & 59 & $6.1 \%$ \\
\hline Per cell $\left(4.4 \mathrm{~cm}^{2}\right)$ & 0.78 & 13.3 & - & - \\
\hline
\end{tabular}

$13 \%$ and $24 \%$ for devices processed from (TMB P\$) and (o$\mathrm{XY}$ Ad) solutions, respectively. The PCE of $9.1 \%$ and $8.0 \%$ measured on devices processed from (TMB $\mathrm{PD})$ and $(0-$ $\mathrm{XY}$ A/A) solutions, respectively, was further reduced when using ITO-free lab-scale solar cells. Surprisingly, the reduction for devices processed from (TMB PNpsolutions was this time more pronounced (almost 21\%) than for devices processed from (oXY AA) solptions (less than 3\%), leading to a final effi- ciency of $7.2 \%$ and $7.8 \%$ for devices processed from (TMB PN) and $\emptyset-\mathrm{XY}$ AA) solutiops, respectively. For modules, an ITO-free cell architecture with $\mathrm{PF} 2 \mathrm{PC}_{71} \mathrm{BM}$ deposited by blade-coating from (o-XY AA) solution waspised with 15 cells

connected in series. A PCE of $6.1 \%$ was measured on a $66 \mathrm{~cm}^{2}$ ITO-free module with a photoactive layer deposited from a non-halogenated solvent solution. This is one of the best performances reported to date for modules larger than $10 \mathrm{~cm}^{2}$.

\section{Supporting Information}

Supporting Information is availablefrom theWiley Online Library or from the author.

\section{Acknowledgements}

This work has received funding from the INTERREG Upper Rhine European Regional Development Fund, the Ministries for Research of Baden-Württemberg, Rheinland-Pfalz, and from the Region Grand Est (a)

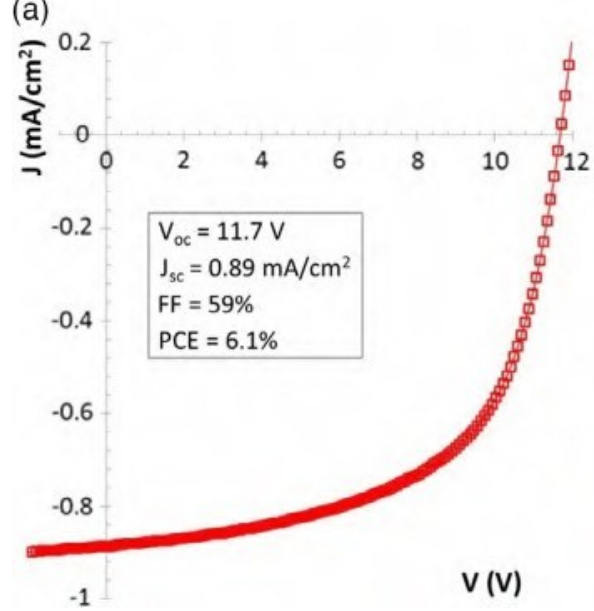

(b)

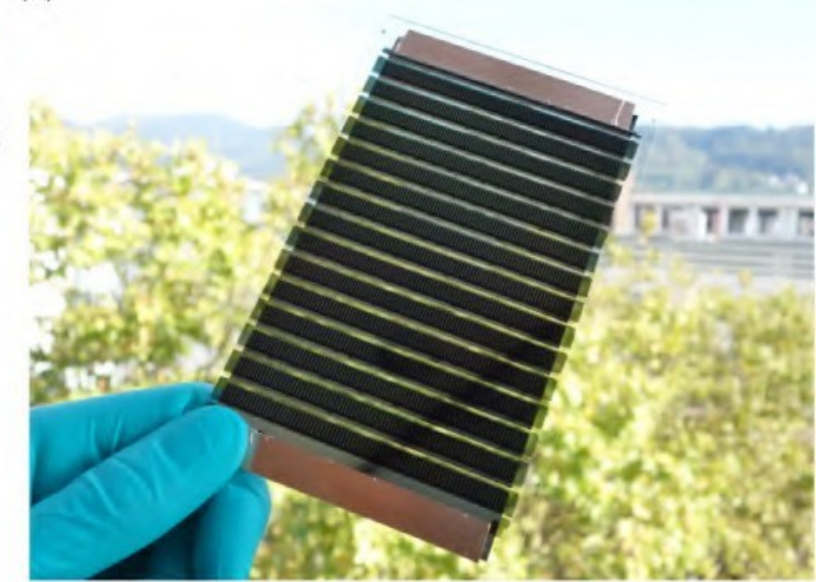

Figure 6. a) $J-V$ characteristics for ITO-free (PF2:PC ${ }_{71} \mathrm{BM}$ ) photovoltaic modules (active area: $66 \mathrm{~cm}^{2}, \mathrm{GFF}: 69 \%$ ). b) Picture of the fabricated OPV modules. 
in the framework of the projectno. 3.10(PROOF). The authors thank the Pohang Accelerator Laboratory (PAL) for giving them the opportunity to perform the GIWAXS measurements, MEST and POSTECH for supporting these experiments, Dr. H. Ahn for adjustments and help, and other colleagues from the 9A USAXS beamline for assistance. The authors thank Dr. U. Vongsaysy from the company Armor and Dr. G. Wantz from the laboratory IMS for fruitful discussions.

\section{Conflict of Interest}

The authors declare no conflict of interest.

\section{Keywords}

harmless additives, indium-free devices, non-halogenated solvents, organic modules

[1] S. Li, L. Ye, W. Zhao, H. Yan, B. Yang, D. Liu, W. Li, H. Ade, J. Hou, I. Am. Chem. Soc. 2018, I 40, 7159.

[2] J. Yuan, Y. Zhang, L. Zhou, G. Zhang, H.-L. Yip, T.-K. Lau, X. Lu, C. Zhu, H. Peng, P. A. Johnson, M. Leclerc, Y. Cao, J. Ulanski, Y. Li, Y. Zou, Joule 2019, 3, 1140.

[3] X. Du, T. Heumueller, W. Gruber, A. Classen, T. Unruh, N. Li, C. J. Brabec, Joule 2019, 3, 215.

[4] S. A. Gevorgyan, M. V. Madsen, B. Roth, M. Corazza, M. Hösel, R. R. Søndergaard, M. Jørgensen, F. C. Krebs, Adv. Energy Mater. 2016, 6, 1501208.

[5] N.Leclerc, P.Chávez, O.A.Ibraikulov, T. Heiser, P.Lévêque, Polymers $2016,8,11$.

[6] P. Cheng, G. Li, X. Zhan, Y. Yang, Nat. Photonics 2018, I2, 131.

[7] C. Zhang, Q. Luo, H. Wu, H. Li, J. La, G. Ji, L. Yan, X. Wang, D. Zhang, J. Lin, L. Chen, J. Yang, C. Ma, Org. Electron. 2017, 45, 190.

[8] K.-M. Huang, Y. Q. Wong, M. C. Lin, C.-H. Chen, C.-H. Liao, J.-Y. Chen, Y.-H. Huang, Y.-F. Chang, P.-T. Tsai, S.-H. Chen, C.-T. Liao, Y.-C. Lee, L. Hong, C.-Y. Chang, H.-F. Meng, Z. Ge, H.-W. Zan, S.-F. Horng, Y.-C. Chao, H. Y. Wong, Prog. Photovoltaics Res. Appl. 2019, 27, 264.

[9] R. Arai, S. Furukawa, Y. Hidaka, H. Komiyama, T. Yasuda, ACS Appl. Mater. Interfaces 2019, I I, 9259.
[10] G. D. Spyropoulos, P. Kubis, N. Li, D. Baran, L. Lucera, M. Salvador, T. Ameri, M. M. Voigt, F. C. Krebs, C. J. Brabec, Energy Environ. Sci. 2014, 7, 3284.

[11] B. Zimmermann, H.-F. Schleiermacher, M. Niggemann, U. Würfel, Sol. Energy Mater. Sol. Cells 2011, 95, 1587.

[12] S. Berny, N. Blouin, A. Distler, H.-J. Egelhaaf, M. Krompiec, A. Lohr, O. R. Lozman, G. E. Morse, L. Nanson, A. Pron, T. Sauermann, N. Seidler, S. Tierney, P. Tiwana, L. M. Wagner, H. Wilson, Adv. Sci. 2016, 3, 1500342.

[13] J. Zhang, Y. Zhao, J. Fang, L. Yuan, B. Xia, G. Wang, Z. Wang, Y. Zhang, W. Ma, W. Yan, W. Su, Z. Wei, Small 2017, 13, 1700388.

[14] O. A. Ibraikulov, C. Ngov, P. Chávez, I. Bulut, B. Heinrich, O. Boyron, K. L. Gerasimov, D. A. Ivanov, S. Swaraj, S. Méry, N. Leclerc, P. Lévêque, T. Heiser, J. Mater. Chem. A 2018, 6, 12038.

[15] C. L. Chochos, M. Spanos, A. Katsouras, E. Tatsi, S. Drakopoulou, V. G. Gregoriou, A. Avgeropoulos, Prog. Polym. Sci. 2019, 9I, 51.

[16] R. Po, G. Bianchi, C. Carbonera, A. Pellegrino, Macromolecules 2015, $48,453$.

[17] C. Sprau, F. Buss, M. Wagner, D. Landerer, M. Koppitz, A. Schulz, D. Bahro, W. Schabel, P. Scharfer, A. Colsmann, Energy Environ. Sci. 2015, 8, 2744.

[18] C.-C. Chueh, K. Yao, H.-L. Yip, C.-Y. Chang, Y.-X. Xu, K.-S. Chen, C.-Z. Li, P. Liu, F. Huang, Y. Chen, W.-C. Chen, A. K.-Y. Jen, Energy Environ. Sci. 2013, 6, 3241.

[19] S. Zhang, L. Ye, H. Zhang, J. Hou, Mater. Today 2016, 19, 533.

[20] S. Roquet, A. Cravino, P. Leriche, O. Alévêque, P. Frère, J. Roncali, J. Am. Chem. Soc. 2006, 128, 3459.

[21] Y. Zhong, L. Biniek, N. Leclerc, S. Férry, M. Brinkmann, Macromolecules 2018, 5I, 4238.

[22] S. Kwon, H. Kang, J.-H. Lee, J. Lee, S. Hong, H. Kim, K. Lee, Adv. Energy Mater. 2016, 7, 1601496.

[23] M. C. Scharber, D. Mühlbacher, M. Koppe, P. Denk, C. Waldauf, A. J. Heeger, C. J. Brabec, Adv. Mater. 2006, 18, 789.

[24] S. Song, Y. Jin, S. H. Park, S. Cho, I. Kim, K. Lee, A. J. Heeger, H. Suh, J. Mater. Chem. 2010, 20, 6517.

[25] M. Kohlstädt, M. Grein, P. Reinecke, T. Kroyer, B. Zimmermann, U. Würfel, Sol. Energy Mater. Sol. Cells. 2013, I I 7, 98.

[26] N. Gasparini, L. Lucera, M. Salvador, M. Prosa, G. D. Spyropoulos, P. Kubis, H.-J. Egelhaaf, C. J. Brabec, T. Ameri, Energy Environ. Sci. 2017, 10, 885.

[27] N. Ren, J. Zhu, S. Ban, AIP Adv. 2017, 7, 055009.

[28] M. Glatthaar, M. Niggemann, B. Zimmermann, P. Lewer, M. Riede, A. Hinsch, J. Luther, Thin Solid Films 2005, 49I, 298.

[29] S. B. Sapkota, A. Spies, B. Zimmermann, I. Dürra, U. Würfel, Sol. Energy Mater. Sol. Cells 2014, 130, 144. 